\title{
Intravenous Iron Sucrose Therapy in Iron Deficiency Anemia in Antenatal and Postnatal Patients
}

\author{
Jyotshna Sharma, ${ }^{1}$ Sanjeeb Tiwari ${ }^{2}$ \\ 'Department of obestritics and gynecology, Kathmandu medical college teaching hospital, Kathmandu, ${ }^{2}$ Department of Emergency \\ and General Practice, TUTH, Maharajganj, Kathmandu, Nepal
}

\begin{abstract}
Introduction: Iron deficiency anemia is the most common nutritional deficiency in pregnancy and more common in developing countries which is aggravated due to increased demand and blood loss during delivery. Though there are different methods for treating iron deficiency anemia. Iron sucrose is being used because of its minimal side effects. This study was undertaken to evaluate the response and effect of intravenous iron sucrose given to patient in antenatal and postnatal period with moderate iron deficiency anemia.
\end{abstract}

Methods: A hospital based prospective study was conducted 1st Jan 2013-30th Dec 2014 in the department of obstetrics and gynecology Kathmandu Medical College, Teaching Hospital Kathmandu, Nepal. Antenatal and postnatal patients with hemoglobin between 5-9 gm\% with diagnosed iron deficiency anemia were included in the study. The aim was to bring her hemoglobin level to $11 \mathrm{gm} \%$.

Results: All together 37 patients were enrolled out of which two patient were dropped due to allergic reaction and 35 patients were included in study. Iron sucrose therapy is effective in achieving target hemoglobin of $11 \mathrm{gm} / \mathrm{dl}$ in $80 \%$ of patients. It showed that intravenous iron sucrose significantly (P $<0.001$ ) increase hemoglobin level within two weeks of therapy without any major adverse effects.

Conclusions: Iron sucrose therapy is safe, effective and well tolerated for the treatment of iron deficiency anemia. Parental iron therapy was effective in increasing hemoglobin, serum ferritin and other hematological parameters in antenatal and postnatal patients with anemia. The treatment will help to reduce the risk of maternal complication during pregnancy and postpartum and its adverse effect to fetus.

Keywords: iron deficiency anemia; intravenous iron; pregnancy.

\section{INTRODUCTION}

Anemia is one of the most common problems encountered during pregnancy. The cause of iron deficiency anemia is due to poor iron containing diet and less interpregnancy interval without any proper supplementation. Postpartum hemorrhage complication is still a leading cause of maternal mortality in developing countries. $20 \%$ of all maternal deaths are contributed to anemia. ${ }^{1}$ The increased need of iron in pregnancy and puerperium leads to increased susceptibility of iron deficiency anemia. During pregnancy iron requirement increases from $1.5-2 \mathrm{mg} /$ day to $5-7 \mathrm{mg} /$ day. ${ }^{2}$ Without adequate stores and with suboptimal intake, iron deficiency anemia may prevail. Guidelines suggest that low hemoglobin levels increases the risk of poor fetal outcomes. ${ }^{3}$ Low iron stores can be readily depleted with blood loss at delivery which may adversely impact the mother's level of fatigue and energy and therefore ability to care for neonates which may result in a prolonged stay in hospital. ${ }^{4}$

The rate of cesarean section has increased now a day. Cesarean section delivery is associated with more blood loss with $1-3 \%$ of patient losing more than $1000 \mathrm{ml}$ blood

Correspondence: Dr Jyotshna Sharma, Department of obestritics and gynecology, Kathmandu medical collage teaching hospital, Kathmandu, Nepal. Email: jyotszee@gmail.com, Phone: +977-9851167722. 
compared to vaginal delivery leading to increase in blood transfusion to treat postpartum hemorrhage. ${ }^{5}$ There are many methods in management of iron deficiency anemia like oral, intramuscular and intravenous preparation of iron depending upon the status and need of pregnant patient ${ }^{6-8}$ but efficacy of the oral iron therapy may be limited in many patients because of dose dependant side effects, non compliance and poor absorption and not possible to achieve the target rise in hemoglobin level in limited time period when patient is approaching the term. ${ }^{7-8}$

In underdeveloped countries like ours anemia is one of the contributory factor to maternal morbidity and mortality. ${ }^{9}$ Inadequate antenatal care along with poor knowledge of dietary needs of pregnant women and overall poor socioeconomic condition are responsible for this in our country. Other Asian countries like Indonesia ${ }^{10}$ and India also report high prevalence of iron deficiency anemia in associated maternal and fetal loss. It is also associated with high perinatal mortality rate. ${ }^{11}$ Iron sucrose is relatively new drug which is used intravenously for the correction of anemia without any severe adverse effects.

The aim of this study was to evaluate the response and effect of intravenous iron sucrose given to patient in antenatal and postnatal period with moderate iron deficiency anemia seen at our institution.

\section{METHODS}

The hospital based prospective study was conducted in the department of obstetrics and gynecology, Kathmandu Medical College Teaching Hospital (KMCTH), Kathmandu, Nepal from $1^{\text {st }}$ Jan 2013-30 ${ }^{\text {th }}$ Dec2013. A total of 37 antenatal and postnatal patients with hemoglobin 5-9 gm\% were included in this study.

Exclusive criteria were other causes of anemia, recent blood transfusion, thalacemia and other medical disorders.

About $10 \mathrm{ml}$ blood sample was taken from patient for peripheral blood smear and detailed serum iron studies which include total iron, total iron binding capacity, serum ferritin level were measured.

Informed consent was taken from all the patients before starting the therapy, baseline investigation including liver, renal function test, urine examination were done.

The formula used for calculation of iron sucrose was

Required iron dose $(\mathrm{mg})=$ (targeted hemoglobin patient's hemoglobin) $\times 250+500$

Encifer (iron sucrose injection, USP) containing $50 \mathrm{mg} / 2.5 \mathrm{ml}$ was single brand used in our study. Iron sucrose was administered as $200 \mathrm{mg}$ elemental iron in $100 \mathrm{ml}$ of $9 \%$ normal saline infusion over one hour everyday up to total calculated dose. A test dose of $1 \mathrm{ml}$ of iron sucrose infusion was given when patient was observed for any allergic reactions. If no reactions occurred the rest of the infusion was given. Hemoglobin level together with iron profile was done on $14^{\text {th }}$ post treatment day.

Blood pressure, pulse, temperature was maintained during infusion of iron sucrose before the start of the infusion and after 15 minutes and at the end of infusion.

Allergic reactions were graded as grade I and grade II and they are described as following:

Grade I reaction was mild to moderate in nature settled with and anti-allergic drug but not requiring discontinuation of the infusion.

Grade II reaction was severe in nature, threatening the patient's life and requiring discontinuation of infusion.

Mean value of hemoglobin, Serum Ferritin and total iron were used to compare pre and post treatment parameters. P-value less than 0.5 were considered to be significant.

\section{RESULTS}

Among 37 patients seven were antenatal patients and rest thirty were postnatal patients. The age of the women ranged from 20-38 years with the mean age of 26. Most of the patients were multigravida. Among 7 antenatal patient mean gestational ages was 31 weeks. Among 30 postnatal patients 18 had gone caserean section and rest 12 had vaginal delivery. All patients were taking oral iron tablets.

There were no allergic reactions in patients in test done but during infusion of iron on one patient develop fever and rigor. So iron infusion was hold and another one developed rashes and itchiness on completing first day dose so iron infusion was hold for subsequent doses on patient's refusal to continue the treatment. No patient had grade II allergic reactions.

\begin{tabular}{|ll|}
\hline Table 1. Complications during iron sucrose infusion. \\
\hline Complications & Number of patients \\
None & 35 \\
Grade I & 2 \\
Grade II & None \\
\hline
\end{tabular}

Before iron sucrose therapy, the mean hemoglobin level was $7.5 \mathrm{gm} / \mathrm{dl}$, mean serum ferritin $12.8 \mathrm{mg} / \mathrm{ml}$, total iron was $40 \mathrm{mg} / \mathrm{dl}$. After iron sucrose therapy, the mean hemoglobin level was $10.3 \mathrm{gm} \%$, mean serum ferritin level was $300 \mathrm{mg} / \mathrm{dl}$ and mean total iron was 
$85 \mathrm{mg} / \mathrm{dl}$. The mean value was calculated manually. The differences were statistically significant as shown by p-values.

\begin{tabular}{|c|c|c|c|}
\hline Investigation & $\begin{array}{l}\text { Before iron } \\
\text { sucrose } \\
\text { infusion }\end{array}$ & $\begin{array}{l}\text { After iron } \\
\text { sucrose } \\
\text { infusion }\end{array}$ & $P$ value \\
\hline $\begin{array}{l}\text { hemoglobin } \\
\text { level }\end{array}$ & $7.5 \mathrm{gm} / \mathrm{dl}$ & $10.8 \mathrm{gm} / \mathrm{dl}$ & $<0.5$ \\
\hline Ferritin level & $12.8 \mathrm{mg} / \mathrm{dl}$ & $300 \mathrm{mg} / \mathrm{dl}$ & $<0.5$ \\
\hline Total iron & $40 \mathrm{mg} / \mathrm{dl}$ & $85 \mathrm{mg} / \mathrm{dl}$ & $<0.5$ \\
\hline
\end{tabular}

\section{DISCUSSION}

Our study showed that iron sucrose therapy can be used in the pregnant patient at both antenatal and postnatal period with iron deficiency anemia. This therapy not only help in the correction of hemoglobin but also for the restitution of iron stores as there was significant improvement in serum ferritin level and iron stores. The significant change can be seen as early as two week post treatment as in our study.

We used hemoglobin and ferritin level to monitor response of hemopoietic system to iron sucrose because of their relative importance in the hemodynamic state of pregnant lady. Due to dilution effect of pregnancy on plasma volume there is a decrease in hemoglobin, haematocrit and red cells count but mean corpuscular volume remains unaffected. ${ }^{12}$ Thus, serial evaluation is useful in differentiating dilution anemia from iron deficiency anemia. Serum ferrtitin is best indicator for assessment of iron stores except for bone marrow biopsy. ${ }^{12-14}$

Oral iron is benig used to correct postpartum iron deficiency anemia. The use of oral iron is limited by its side effects poor compliance and the fact that it takes a long time to correct low hemoglobin and iron stores taking 40 days in one study before a satisfactory maximum effect was reached. ${ }^{15}$

Intravenous iron sucrose has been also compared to intramuscular iron sorbitol in which iron sucrose is more effective and $20 \%$ of the patient in sorbitol group dropped out of the study due to intolerance. ${ }^{16}$ Intravenous iron sucrose interfere with lactation, emphasizing previous reports of active biological memory glands regulation of milk iron concentration. ${ }^{17}$ Intravenous iron sucrose avoids the risk associated with blood transfusion, complication and hazards of blood transfusion and is more cost effective. ${ }^{18}$

Intramuscular iron preparation in treating iron deficiency anemia is discouraged because of pain, irregular absorption and staining. Up to $30 \%$ of patients who were given iron dextran suffer from adverse effect which includes arthritis and fever, urticaria and anaphylaxis. ${ }^{12}$ Similar study was done by Suchita Patel which showed $80 \%$ rise in hemoglobin in four weeks post treatment period which was significant.

Study done with comparison of oral iron and intravenous iron sucrose treatment showed significant improvement in various hematological parameters in intravenous iron sucrose group as compared to patients in oral iron group in short time interval. ${ }^{13}$

In general, once acute homeostasis and hemodynamic stability around delivery has been achieved, the anemia can be treated by intravenous iron. Although, intravenous iron sucrose therapy may appear invasive, expensive and time consuming, it is highly and rapidly effective in correcting anemia without major side effects which make it convenient and cost effective in pregnant iron deficient women who are unable to obtain an adequate amount of iron rapidly by oral rout. In our study with the limited number of patients and power of the study, the study demonstrates that intravenous iron sucrose therapy is almost as effective as blood transfusion, so our study has statistically significant finding demonstrating a better rise in hemoglobin in one week.

\section{CONCLUSIONS}

This study showed significant improvement of hemoglobin and iron store in antenatal and postnatal women given calculated dose of intravenous iron sucrose. It is safe and well tolerated. In country like ours where there is high prevalence of iron deficiency anemia during pregnancy, this treatment will definitely help in management of these patients.

\section{REFERENCES}

1. Nyuke RB, Letsky EA. Etiology of anemia in pregnancy in South Malawi. American Journal Clinic Nutritition 2000; 72:247-256.

2. Bothwell $\mathrm{TH}$, Iron requirements in pregnancy and strategies to meet them. Am J Clin Nutr. 2007;72(1)S257-S264.

3. National Institute for Health and Clinical Excellence. Antenetal care: Routine Care for the Healthy Pregnant Women. Clinical Guideline. London, UK: National Institute for Health and Clinical Excellence; 2008.

4. Bashiri A, Smolin A, Sheiner E, Zelingher J, Mazor M. Maternal rehospitalization after singleton term vaginal delivery. J Matern Fetal Neonatal Med. 2003; 14(5):344-348. 
5. Knight M, Callaghan WM, Berg C, et al. Trends in postpartum hemorrhage in high resource countries: A review and recommendations from the International Postpartum Hemorrhage Collaborative Group. BMC Pregnancy Childbirth. 2009;9:55.

6. Bayoumeu F, Subiran-Buisset C., Baka NE, Legagneur H, Monnier-Barbarino P, Laxenaire MC. Iron therapy in iron deficiency anemia in pregnancy: intravenousroute verses oral route. Am J Obstet Gynaecol 2002: 186:518-22.

7. Perewusny KG, Huck R, Huck A, Breymann C. Perental ironsucrose complex.Br J Nutr 2002;88:3-10.

8. Al-Momen AK, al-Meshari A, al-Nuaim L, Saddique A, Abutablib Z, Khashogi $\mathrm{T}$, et al. Intravenous iron sucrose complex in the treatment of iron deficiency anemia during pregnancy. Eur J Obstet Gynecol Report Biol 1996; 69:121-4.

9. Saeed M, Khan TA, Khan SJ. Evaluation of risk factors in antenatal care. Mother and child 1996; 34:139-42..

10. Suega K, Dharmayuda TG, Sutarga IM, Bakta IM. Irondeficiency anemia in pregnant women in Bali, Indonesia: a profile of risk factors and epidemiology Southeast Asian J Trop Med Public Health 2002; 33:604-7.

11. Khosla AH, Dahiua P, Dahiya K. Burden of chronic severe anemia in obsteric patients in Rural North India, Indian J Med Sci 2002; 56:222-4.
12. Breymann C \& Anemia working group. Current aspects of diagnosis and therapy of iron deficiency anemia in pregnancy. Schweiz Rundsch Med Prax 2001; 90:1283-91.

13. Breymann C. Iron deficiency and anemia in pregnancy: Modern aspects of diagnosis and therapy. Blood Cells Mol Dis 2002; 29:506-16.

14. Alper BS, kimber R, Reddy AK. Using ferritin levels to determine iron deficiency anemia in pregnancy. J. Farm Pract 2000; 49:829-32.

15. Bhandal N, Russel R. Intravenous vs. Oral iron therapy for postpartum anaemia. BJOG2006:113:1248-52.

16. Wali A, Mushtaq A. Comparative study-Efficacy, safety and compliance of intravenous iron deficiency anemia in pregnancy. J Pak Med Assoc Sep 2002; 52(9):392-5.

17. Breymann C, von Seefried B, Stahel M, et al. Milk iron content in breast-feeding mothers after administration of IV iron sucrose complex. J Perinatal Med 2007; 35 (2): 115-8.

18. Bozhinova S, Ivanova I, Lukanova M. Howe to avoid a haemo transfusion which is not life saving? Our experience with administration of IV Iron to pregnant women and young mothers. Kush Gynaecol Sofia 2004; 43(6): 13-7. 